\title{
Teaching Research of Accounting Informatization Flipped Classroom Based on SPOC*
}

\author{
Ruigong Wang \\ Applied Accounting Department \\ Xijing University \\ Xi'an, China 700123
}

\begin{abstract}
Under the historical background of "Internet +", the education informatization has become the key of current teaching background and the informatization reform of college courses is imperative. This thesis takes the Accounting Informatization course as an example to analyze the features of SPOC web-based instruction platform, flipped classroom and mind mapping and microlecture. Based on SPOC platform, supported by the informatization technology, the course teaching resource as a tool, the research of Flipped Classroom teaching reform is developed around three aspects: design of teaching content, design of teaching activities and design of teaching evaluation. Oriented by the course, the relevant teaching design system is built, the application of informatization technology on the teaching is discussed and the Flipped Classroom teaching practice of course is reflected on teaching to play a reference function in the informatization reform and optimization of relevant course.
\end{abstract}

Keywords-SPOC; accounting informatization; flipped classroom; teaching research

\section{INTRODUCTION}

The rapid development of information technology and wide application of Internet enable the teaching informatization has become the important motive power to promote the reform and development of teaching. In March 2012, Ten-year Plan for the Development of Education Informatization (2011-2020) issued by Ministry of Education pointed out that the level of education informatization on the integration of information technology and education will be significantly improved and fully show the leading effect on the education reform and development until 2020. On February 2, 2016, the Ministry of Education issued the Working Focus of Education Informatization in 2016, guiding universities and college to utilize the online open courses to search the reform of Flipped Classroom and other teaching methods. The guidance of Chinese national policies and the demands of market on Accounting Informatization personnel accelerate that the Accounting Informatization course should closely follow the historic reform and develop the teaching reform to satisfy the requirements of talent training under the informatization environment.

*CLC number: G431 Document code: A

*Topic Source: School-level teaching reform research project, project number: GZJGYB1721
Accounting Informatization is a professional basis course of finance and accounting profession. The Course requires students to know basic principles of Accounting Informatization, master the applications of accounting software, have analysis ability of accounting information system and be qualified in the accounting work under the enterprise informatization environment. Yang Yiqing[1] thought, in the "Effective Combination of Accounting Computerization and Modern Information Technology", that the information society and Internet times require us to enable the accounting work to more effectively service the operation process of enterprises' economic management under the accounting thoughts of information technology, system theory and informatization. On the basis of the effective teaching design model based on Flipped Classroom concept under informatization environment, Zhong Xiaoliu, et al. [2] in Tsinghua University thought, in "Teaching Design Study Based on Flipped Classroom Concept under Informatization Environment", that the application of Flipped Classroom in the informatization environment in the classes facilitates to truly realize the individualized teaching and independent learning whose center is students; Zhao Xinglong[3] thought, in "Knowledge Internalization Process and Teaching Model Design in Flipped Classroom, that when the Flipped Classroom is implemented, the advance of knowledge instruction brought by the reform of teaching process and the optimization of knowledge internalization should resolve the difficulty degree of knowledge internalization and increase the frequency of knowledge internalization based on the flipping of teaching process so that the learners can gain the knowledge. He Kekang [4] deeply discussed the true connotation and essence of "Flipped Classroom" from six aspects: the essence of "Flipped Classroom", the future development of Flipped Classroom in China, the origin, the development, the function and the effects of "Flipped Classroom" and thought that the core of future development of Flipped Classroom in China is to achieve the fundamental reform of class teaching structures.

However, the study of above literatures can't describe the specific teaching reform of courses for the study of the informatization and Flipped Classroom. Especially, for the teaching study of Accounting Informatization Flipped Classroom, the design and study of course practice teaching based on the campus network platform and the teaching 
situation of enterprise posts is lacked. Therefore, this thesis builds a teaching model of Accounting Informatization Flipped Classroom based on SPOC in accordance with the teaching content, teaching activities and teaching evaluation to deeply study the course teaching. SPOC (Small Private Online Course), Flipped Classroom and course are interactively designed, the online study platform is built in virtue of SPOC to push the diversified teaching resources, service class teaching and the Flipped Classroom is applied to achieve the internalization of knowledge points and improve the practice operation skills and software application ability of students.

\section{CHARACTERISTICS OF COURSE FLIPPED CLASSROOM INFORMATIZATION BASED ON SPOC}

\section{A. SPOC Course Platform}

The traditional class study is limited by time and places and is unable to optimize the time utilization condition after school of students so that the students' cognition on the knowledge points, emotion of study and motility of practice can't be organically integrated in the classroom study. Prof. Lue from Harvard University thought that the significance of SPOC is to enable online study tries to surpass the copy of current classroom courses and create more flexible and effective things [5].At present, the campus SPOC course platform mainly aims at the students of our university, so the "limitation" of SPOC enables the students whose applications are approved feel superiority and sense of responsibility within limited permission. The SPOC course platform is embedded into the teaching situations of entity classroom to present the course structure and knowledge system by mind mapping based on the SPOC of screen, show the key information and operation process via microlecture video, accurately check the knowledge study through item test and clearly feedback the study effect based on microblog forum. Application of SPOC class platform in the entity classroom can fully utilize the students' time before and after class beyond the classroom teaching, fully make full use of the modern information technology in the teaching, build a modern study situation for students and mobilize students' thoughts to actively participate in the course study. In general, SPOC is beneficial for students to produce their own study motility and effectively guarantee the study effect [6], enabling to provide important resource support for the entity classroom teaching and lay a foundation for the class study.

\section{B. Flipped Classroom}

In the traditional course teaching, teachers explain or demonstrate and students study or imitate to achieve the effect to strengthen the knowledge and the practice ability of students. However, in the actual teaching process, students lack of the knowledge recognition before class and have no emotion to actively participate in the course study so that students just passivity listen and simulate, lack of independent thoughts and team collaboration and can't understand and apply the knowledge. Flipped Classroom will adjust the study in and after school and optimize the teaching process before, in and after class to achieve the effective flipping of entity classes. Before class, by means of task assignment in the SPOC course platform, students study online and finish the task driven by the task. In class, under the preparation work before class, teachers arrange the teaching activities in the entity classes, comprehensively answer questions and disabuse students and organize students for situational simulation and cooperate discussion to effectively motivate students and enable students to focus on the practice, discussion and interaction, improve their cognition degree of knowledge points, deepen their emotion to actively participate in the study, fully exercise students' independent study ability and team collaboration ability and "help students achieve personalized study" [7]. After class, task assignment enables students to consolidate their knowledge through online and offline study to build "a knowledge network whose framework is core concept" [8] of project.

\section{Mind Mapping}

Mind mapping, also called as mind map, "enables people to clearly describe the routes and levels of thoughts by means of map and simulate the left and right brain to reify and visualize the divergent thinking by means of the most familiar image for brain, is an effective tool to organize and express knowledge and the source of inspiration and divergent thinking" [9].Mind mapping is centered on the core knowledge points of project and takes the key points of knowledge system as the nodes so that students built their own knowledge framework based on visual cognition structure and concept frame and can tease out knowledge and excavate the key and difficult points hereby. The special "atlas" [10] in the mind mapping can promote students to connect the learnt knowledge and the knowledge to be learnt in the study and recall and associate the relevant atlases; besides, it can promote students to make homogeneous understanding for the new knowledge subconsciously and form clear skeleton in the thought by integration and convergence. Therefore, in general, mind mapping can include the core knowledge points in the whole knowledge system via tidy map to provide the study resources for students' active cognition, promote the interaction between teachers and students in and after school, build a kind of active and open learning atmosphere and motivate the learning interests of students. Meanwhile, teachers can teach students the technology of mind mapping making via software and make students make a mind mapping of a certain project in accordance with their own knowledge understanding and report and share it to improve the motivation of students' independent study. On the application of mind mapping in Flipped Classroom, teachers should comprehensively summarize and recombine the cognition processes of students to provide practice resources for the further teaching design optimization in later stage.

\section{Microlecture}

Microlecture, as a kind of teaching tool produced under the condition of modern information technology, is supported by the multimedia technology to record the knowledge points around the course in the teaching process 
or the whole process of key teaching activities. Li Jiahou [11] thought that the microlecture should be a small course which has clear teaching goals and short content with less than 10minute video and can explain a problem. Microlecture has following characteristics in the education teaching: First, targeting. The teaching key points are prominent, one microlecture video aims at one core knowledge with dynamic screen image so that the teaching goals can be achieved in the most effective time. Second, micromation. Every microlecture video is 5-8 minutes and uses a little space, convenient to repeatedly play on the Internet platform and mobile platform. Third, sharing. Under the modern information technology environment, the microlecture, as a new web-based instruction tool, breaks the course knowledge points to pieces and shares the resources via the Internet platforms, conducive to the communication, thinking expansion and course design optimization among teachers. The microlecture has obvious characteristics which can play a resource-supporting role in the Flipped Classroom teaching and can achieve the study guidance and consolidation outside the entity classroom. Before class, via the microlecture video, students preview the knowledge and tease out the key, difficulties and problems in accordance with their own study ability. The microlecture video motivates the thirst for knowledge and promotes students to study with the emotion to seek knowledge in class. After class, in accordance with the study before and in class, students utilize the microlecture to review and consolidate knowledge points, make extended thinking and digest the knowledge. Therefore, microlecture can effectively promote the integration of "teaching and study" under the current background of education informatization.

\section{COURSE BACKGROUND OF ACCOUNTING}

\section{INFORMATIZATION FLIPPED CLASSROOM BASED ON SPOC}

Accounting Informatization course is to improve the students' ability of accounting software application and financial analysis. After the practical exploration, the Accounting Informatization Flipped Classroom based on SPOC is the teaching research which "inverts the traditional classroom knowledge instruction and knowledge internalization" [12], effectively utilizes the SPOC course platform to make and integrate the course network resources and develops the Flipped Classroom combined with the enterprise post background under the market economic condition. The course puts the accounting software application and financial analysis in the scenario of the "enterprise" accounting information system under the market economy. Students are divided into several groups, then each group selects their group leader by themselves and confirm their enterprise' name, next, the group members respectively take up the posts of CFO, General Ledger Accountant, cashier, auditor, wage accounting, external financial accounting report and so on. The teacher remind students that one person can hold only one post or several pots (but the cashier can't hold the post of auditor, accounting archivist and register of earning, cost and debt accounts), or several persons hold one post. In the teaching design, the enterprise characters and post responsibilities are introduce into the software application and financial analysis of Accounting Informatization and the teaching content is designed, pushed, arranged and examined via the SPOC platform in accordance with the independent learning, collaborative learning, inquiry-based learning and other education teaching concepts to promote the situational construction of students on the course content and intensify the participating awareness and competitive awareness of students in the situational simulation of enterprise posts under the market economic condition. After receiving, analyzing, learning and summarizing the knowledge points, students store their own knowledge and build the connection with learning situation to realize the construction of knowledge system and promote that students understand and apply the course knowledge. Thereby students' learning interests are effectively motivated, the independent learning ability, teamwork ability and language expression ability are trained and the decisionmaking power of students' learning transform from teachers to students.

\section{TEACHING Design OF ACCOUNTING INFORMATIZATION FLIPPED CLASSROOM BASED ON SPOC}

The teaching design of Accounting Informatization Flipped Classroom based on SPOC course platform is strategically based on the enterprise's financial posts under the market economic condition to provide students with true, vivid and open teaching environments and learning scenarios, motivate the positivity, motility and innovation; tactically, via the design of the teaching content, teaching activities and teaching evaluation, builds the teaching system for Accounting Informatization course teaching to achieve the systematization of learning. Teaching content is centered on the knowledge learning and practical operation of system management, general ledger system, subsystem and financial statement system for the arrangement of class activities; teaching activities are oriented by the task arrangement before, in and after class to enable students to cognize and internalize the learnt knowledge based on the application of SPOC platform and the acting of characters of enterprise posts in class; teaching evaluation builds the diversified evaluation system which highlights the process assessment via the learning and sharing of SPOC course platform resources and the competition, achievement exhibition and interaction among enterprises in class.

\section{A. Design of Teaching Content}

The teaching content of Accounting Informatization Flipped Classroom based on SPOC mainly involves the cognition of Accounting Informatization, and the application of system management platform, general ledger system, subsystem (including wage management system, fixed assets management system, etc.) and statement system. The course intensifies the students' knowledge ability and improves the practical ability based on the project module and practical process. The structure figure of teaching content design is shown in "Fig. 1". 


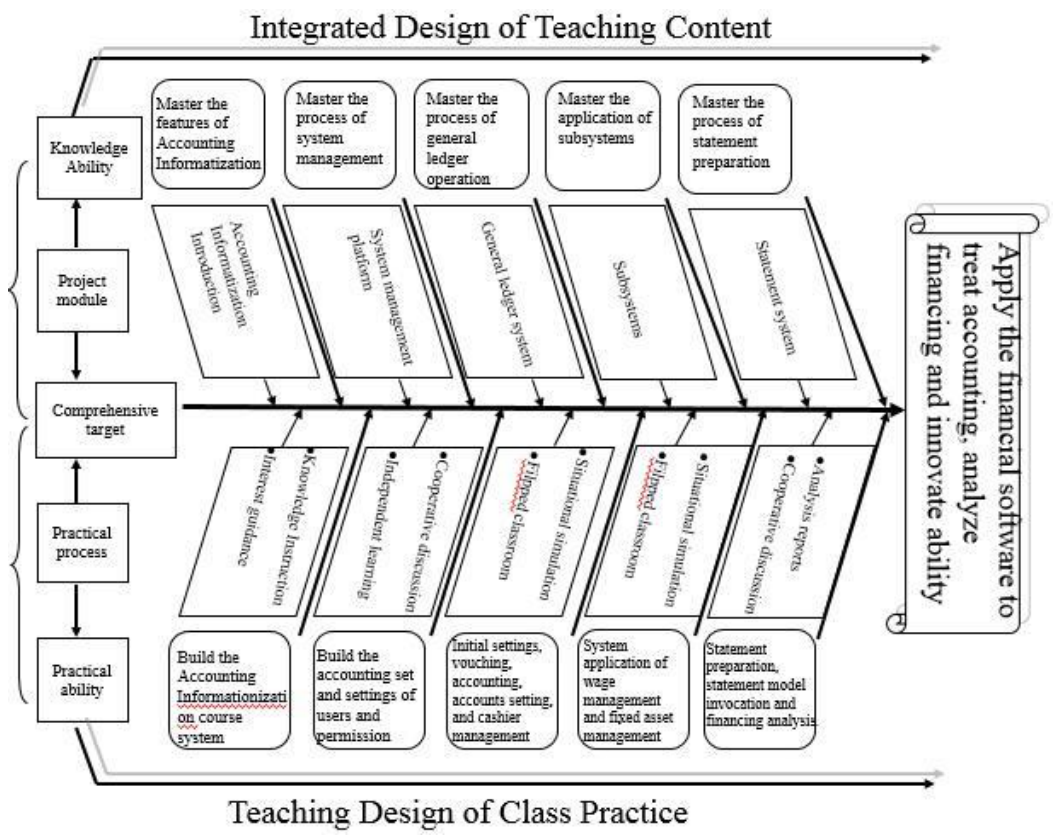

Fig. 1. Structure figure of teaching content design.

The teaching arrangement of Accounting Informatization integrates the theory teaching and practical teaching and pushes the course resources online base on SPOC platform. Guided by the learning of theory knowledge points, the course content motivates the learning interests of students via the diversified teaching methods, develops the practice of knowledge application, examines the mastery condition of knowledge in practice and promotes the understanding and application of knowledge. Specifically, in the training of knowledge ability, on the basis of the enterprise operation and financial processing, the course content is processed with integrative design, the meanings, characteristics and development of Accounting Informatization are mastered based on the learning of Accounting Informatization introduction and the operation processes of different systems and the interrelation between specific applications and systems are mastered. The training of practical ability highlights the course design of practical teaching, is guided by process practice and enable students to interest the Accounting Informatization course by means of the interest guidance and knowledge instruction and builds the systematic cognition; by the means of independent learning and cooperative discussion, enables students to expertly master and flexibly apply the account set establishment of system management and settings of users and permissions; by the means of situational simulation and Flipped Classroom, sets the knowledge system of general ledger system and relevant subsystems and enables students to master the keys which should be noticed in the active exploration and accumulated operation in the initial settings, vouching, accounting, accounts setting, cashier management and other operation process, to learn teasing up the operational processes of different subsystems and the logical relationship between different subsystems and general ledger system and to improve the ability to analyze and solve problems in the practical application from simple to deep, from general to special and drawing inferences about other cases from one instance; by means of cooperative discussion and analysis report, enables students to untangle the system skeleton, to clear the making process of statements and the analysis of statement data and to improve the ability of financial analysis and decisions. In general, the design of teaching content targets the training of knowledge ability and practical ability to achieve the training of the ability of accounting treatment, financial analysis and innovative application to students via the financial software.

\section{B. Design of Teaching Activities}

The design of teaching activities of Accounting Informatization Flipped Classroom based on SPOC is guided by the situational simulation of enterprise's financial posts and is supported by the small-scale and restricted SPOC course platform and the design and role play of enterprise posts to build a good teaching atmosphere. The entire teaching activity is designed from three parts: before class, in class and after class. The structure figure of teaching activity design is shown in "Fig. 2".

Before class: teachers assign the learning tasks towards students, push the course resources to the SPOC course platform. The data based on the SPOC course platform cover the whole course and the mind mapping, microlecture videos, operation processes, tests, forums of different projects. Students clear the learning tasks and log in the course platform to develop the network learning. The mind mapping can achieve that students systematically cognize the course and projects, the learning of microlecture videos and project operation processes can make students intuitively master the detailed operation and students finish the project tests by independent learning.3-4 students are a group. A group builds a enterprise, clears the responsibilities, deeply develop the cooperative discussion, summarizes the key, difficulties 
and problems, issues the summarizing information in the forum blog of SPOC course platform and forms the paper materials to well prepare the class practical applications. Teachers master the online learning time, learning behaviors and communication conditions in accordance with the SPOC course platform, clear up the intelligent analysis data of students' independent learning and learning interaction conditions and continuously optimize the learning resources and learning tasks in the SPOC course platform.

In class, the practice of Accounting Informatization Flipped Classroom based on the SPOC course platform is based on the online learning before class. Teachers explain the difficult points in class against the feedback in the SPOC course platform and set the situations based on the enterprises built by each group. Members of each group ensure the personnel of accounting posts in its enterprise and clear the responsibilities of general ledger posts, cashier posts, auditor posts, wage accounting posts, posts of the receiving and dispatch of assets, goods and materials and the accounting increase and decrease and posts of the preparation of external financial and accounting reports. Teachers release tasks and each enterprise develops the discussion and practice of Accounting Informatization financial treatment and makes plans of project design. The competition among enterprises can effectively motivate the participation and motility of each member, students fully play a leading role in learning and teachers give some assistance. During the processes of demonstration program and PPT report, each enterprise appoints the representative to demonstrate the operation processes, explain the solutions of project design and propose the attentions and matters, other enterprises put questions to this demonstration enterprise, the enterprise gives comprehensive answers, then other enterprises evaluate this enterprise in accordance with the comprehensive performance. Teachers participate the whole teaching process, give the comprehensive evaluation for each enterprise in accordance with their class performance and make a summary for the learning processes and learning effects of students. During the whole course teaching of Flipped Classroom based on SPOC, in accordance with the feedback information of students on the SPOC course platform, the systematic demonstration of classes, PPT reports, questions and comments and other interaction activities, teachers comprehensively tease up the key points and form a key-point knowledge base to provide the resource support of operation application for students in the future and promote that students can more deeply cognize the learning content.

After class: after the learning, practice and reports in class, students upload the homework, finish the online tests and share high-quality resources in the SPOC course platform. Meanwhile, members of each enterprise mutually summarize the key and difficulties and share the learning experience and reflection; gather the opinions and suggestions of each enterprise. By the means of the online interaction, online messages and online evaluation, the interaction between teachers and students, students and students is achieved to consolidate the learning results. In accordance with students' feedback of teaching methods, team collaboration, situational simulation, knowledge mastery and other conditions, teachers continuously summarize and rethink the teaching process, optimize the design scheme of teaching reform and perfect the construction of teaching resource base. 

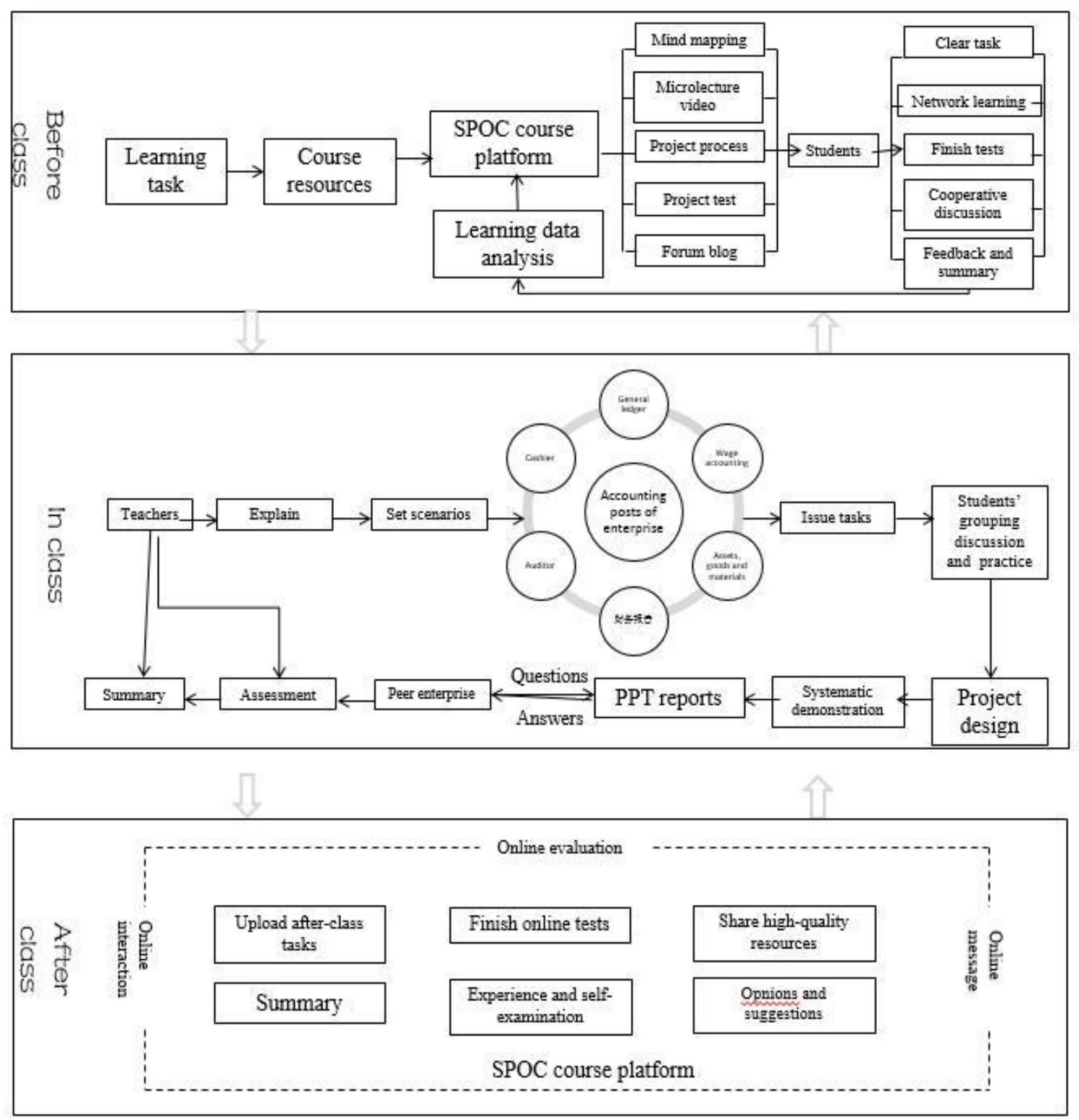

Fig. 2. Structure figure of teaching activity design.

\section{Design of Teaching Evaluation}

In the teaching of Accounting Informatization Flipped Classroom based on SPOC course platform, the single evaluation system has not satisfied current teaching requirements and the systematization and systematism of the teaching content and teaching activities require the course evaluation system also should form relevant systematic frameworks. Therefore, Accounting Informatization course highlights the process assessment of students' learning participation to build the diversified teaching evaluation system which confirms to the course nature.The structure figure of teaching evaluation design is shown in "Fig. 3". 


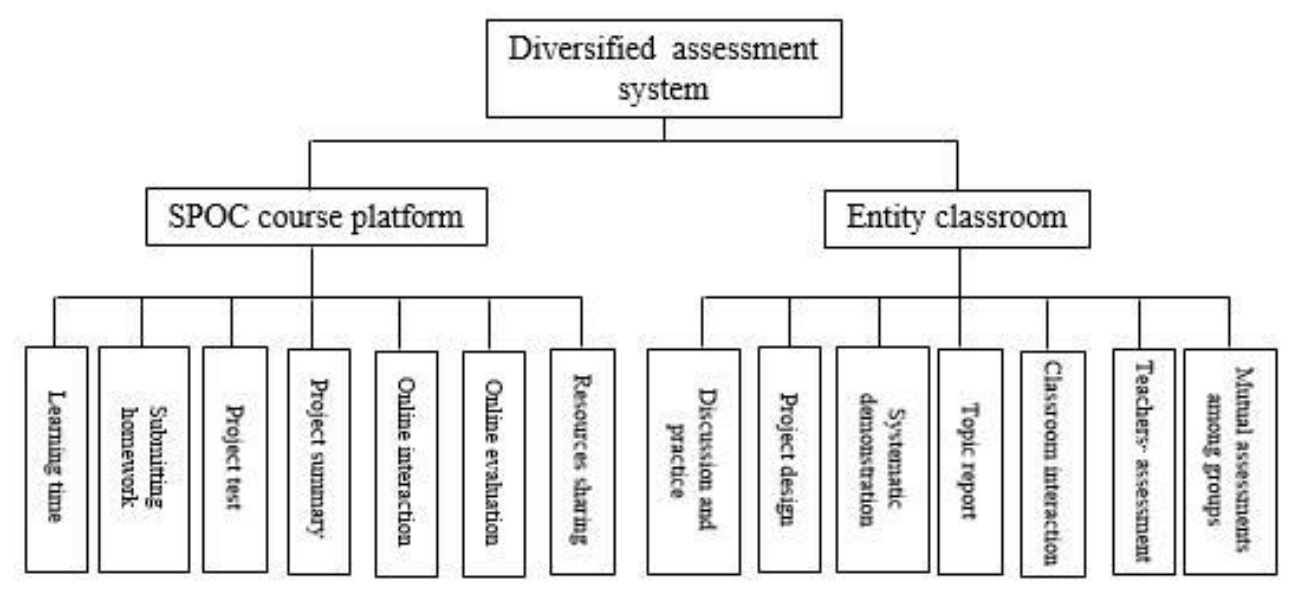

Fig. 3. System diagram of teaching evaluation design.

The diversified evaluation system of course qualitatively and qualitatively evaluates from two aspects: SPOC course platform and entity classroom. First, make comprehensively quantitative evaluation in accordance with the time of independent learning, number of task submitting and grade of project tests of students in the SPOC course platform; make qualitative evaluation in accordance with the project summary condition, online interaction, online evaluation and the participation frequency and number of times of sharing high-quality resources. Secondly, make quantitative evaluation in accordance with the project design processes of each enterprise, the systematic demonstration processes, teachers' assessment, mutual evaluation among groups; make qualitative evaluation in accordance with the discussion practice, topic reports and class interaction of students in the class projects. About the design of score distribution, the assessment of SPOC course platform is $40 \%$ and that of entity classroom is $60 \%$. The bidirectional and diversified teaching evaluation of Accounting Informatization Flipped Classroom can comprehensively assess the comprehensive ability of students, pay attention to the dynamitic preparation degree of every student in the whole learning processes and intensify the integration degree of independent learning and team collaboration of students. In the assessment process, students also can more deeply make learning selfexamination to lay a foundation for the further learning.

In general, the teaching of Accounting Informatization Flipped Classroom based on the SPOC is designed around the teaching content, teaching activities and teaching assessment, the integrative design of teaching content provides the flipped design of teaching activities with practical basis and the activities of flipped teaching promotes the construction of the diversified teaching assessment system. Three are linked with one another. In general, the teaching provides students with the open scenarios of the enterprise's financial posts under the market economic condition, manifests the personal characteristics of students, improve the comprehensively practical skills of students, motivate the creative awareness of students and lay a foundation to train the applied talents who conform to the demands of society economic development.

\section{Teaching Thoughts of AcCounting INFORMATIZATION FLIPPED CLASSROOM BASED ON SPOC COURSE PLATFORM}

\section{A. Teaching Content and Course Targets Fit in with Each Other}

After the learning of the Accounting Informatization course, students can skillfully master the operation process and application skills of UFIDA ERP-U8 (V10.1) which is available for the financial data processing and analysis of enterprise, can independently analyze the financial results and provide the information of financial decisions. Teachers collect the learning willingness, learning features and learning ability of students based on the analysis of learning conditions and designs the teaching content in the means of Internet platform and diversified informationalized teaching method. In the Flipped Classroom design based on SPOC course platform, the theoretical knowledge and applied knowledge should be distinguished to confirm whether the flipped content is accepted or rejected and the teaching content of Flipped Classroom should be designed in means of situational simulation, systematic demonstration, PPT reports and other diversified methods.

\section{B. Teaching Activities And Course Tasks Fit in with Each Other}

In the teaching activities of Accounting Informatization Flipped Classroom based on the SPOC course platform, teaching should be arranged based on the time points before, in and after class and every link should focus on the students from the knowledge preparation, software application to knowledge internalization. Targets between teachers and students synergize. Through the design of teaching activities, students target to finish the course tasks in the teaching activities and carefully learn and practice the Accounting Informatization systems and main operation methods of every system in the course. After the learning of this course, students can draw inferences about other cases from one instance, maser the application skills of Accounting Informatization systems under the Internet background, experience the learning process in the scenarios, improve 
their skills in the experiences and then internalize the knowledge.

\section{Teaching Assessment and Course Requirements Fit in with Each Other}

Accounting Informatization builds the diversified teaching assessment system emphasized on process assessment and make qualitatively and quantitatively comprehensive assessment for the learning conditions of students from two aspects: SPOC course platform and entity classroom, where, the assessment standard should confirm to the requirements of course on students and the evaluation content should be designed based on the specific requirements of learning projects. In accordance with the different assessment content, in order to confirm the effectiveness and fairness of assessment, the relevant assessment standards should be made in accordance with the personal online and offline performance, the personal learning results and the performance of discussion and practice of group collaboration, the presentation of group work and other respects of students and the diversified score accumulation method should be applied to motivate the enthusiasm and initiative of students on the course learning.

\section{CONCLUSION}

The teaching of Accounting Informatization Flipped Classroom based on the SPOC is designed around the teaching content, teaching activities and teaching assessment, the integrative design of teaching content provides the flipped design of teaching activities with practical basis and the activities of flipped teaching promotes the construction of the diversified teaching assessment system. Three are linked with one another. In general, the teaching provides students with the open scenarios of the enterprise's financial posts under the market economic condition, manifests the personal characteristics of students, improve the comprehensively practical skills of students, motivate the creative awareness of students and lay a foundation to train the applied talents who conform to the demands of society economic development.

\section{REFERENCES}

[1] Yang Yiqing, Effective Combination of Accounting Computerization and Modern Information Technology [J], China Collective Economy, 2012, (4):154-155.

[2] Zhong Xiaoliu, Song Shuqiang and Jiao Lizhen, Teaching Design Study Based on Flipped Classroom Concept under Information Environment [J], Open Education Research 2013,(1):58-64.

[3] Zhao Xinglong, Knowledge Internalization Process and Teaching Mode Design in Flipped Classroom [J], Modern Distance Education Research, 2014,(2):55-61.

[4] He Kekang, See Future Development of "Flipped Classroom" in China from Essence of "Flipped Classroom" [J], E-education Research, 2014,(7):5-16

[5] Coughlan,S..Harvard plans to boldly go with 'Spocs' [EB/OL]. http://www.bbc.com/news/business-24166247, 2014-07-10.

[6] Yang Zhujun and Zheng Qi, Primary Exploration of MOOC and Other Online Education Mode, 2014,(2):9-12.
[7] Song Yanling, Meng Zhaopeng and Yan Yajuan, Research of Flipped Classroom from Cognitive Load - and Analysis of Typical Modes of Flipped Classroom [J], Journal of Distance Education, 2014,(1):105112.

[8] He Bin and Cao Yang, SPOC: Innovation of Teaching Process Base on MOOC, China Educational Technology, 2015,(3):22-29.

[9] Novak,J.D., Gowin,D.B. Learning how to learn[M]. New York: Cambridge University Press, 1984.

[10] Zhao Jiana, Research of Application Mode of Mind Mapping in Construction of Cognitive Structure - Take College Basic English Practice Course as an Example [J], China Educational Technology, 2014,(7):121-126.

[11] Li Jiahou, Significance and Development of Microlecture [J], Information Technology Education of Middle and Primary Schools, 2013,(4):12-14.

[12] Yang Jiancai, Dongyan and Guo Qiaoyun, Experimental Research of Mind Mapping in Chinese Teaching of Singapore Primary Schools [J]. China Educational Technology, 2007,(10):65-68. 